\title{
Heartbeat: cardiovascular health in the time of COVID-19
}

doi:10.1136/heartjnl-2020-318627

Catherine M Otto

The COVID-19 pandemic continues to negatively impact population health by indirect effects on patient and healthcare systems, in addition to the direct effects of COVID-19 itself. Accurate and quantitative information about the indirect effects of the COVID-19 pandemic on cardiovascular disease (CVD) services and outcomes will allow better public health planning. Ball and colleagues ${ }^{1}$ aim to 'design and implement a simple tool for monitoring and visualising trends in CVD hospital services in the UK' and towards that end they present pilot data from a preliminary cohort of nine UK hospitals in this issue of Heart. Comparing 6 months in 20192020 (that include the COVID-19 lockdown in the UK) to the same time period in 2018-2019, there was a $57.9 \%$ decrease in total hospital admissions and a 52.9\% decrease in emergency department visits (figure 1). In addition, there was a $31 \%-88 \%$ decline during lockdown in procedures for treatment of cardiac, cerebrovascular and other vascular conditions.

From the other side of the world, Brant and colleagues ${ }^{2}$ report the number of cardiovascular deaths in the six Brazilian cities with the greatest number of COVID-19 deaths. They conclude: 'Excess cardiovascular mortality was greater in the less developed cities, possibly associated with healthcare collapse. Specified cardiovascular deaths decreased in the most developed cities, in parallel with an increase in unspecified cardiovascular and home deaths, presumably as a result of misdiagnosis. Conversely, specified cardiovascular deaths increased in cities with a healthcare collapse' (figure 2).

In the accompanying editorial, Watkins ${ }^{3}$ notes that 'Taken together, these two studies quantify what many readers of this journal have experienced firsthand: the restructuring of hospital services to cope with an influx of COVID-19 cases, combined with social distancing measures, has severely limited access to cardiovascular care, adversely impacting patient outcomes.' He then goes on to propose policy responses to reduce all-cause death among patients with CVD including

Correspondence to Professor Catherine M Otto, Division of Cardiology, University of Washington, Seattle, WA 98115, USA; cmotto@uw.edu

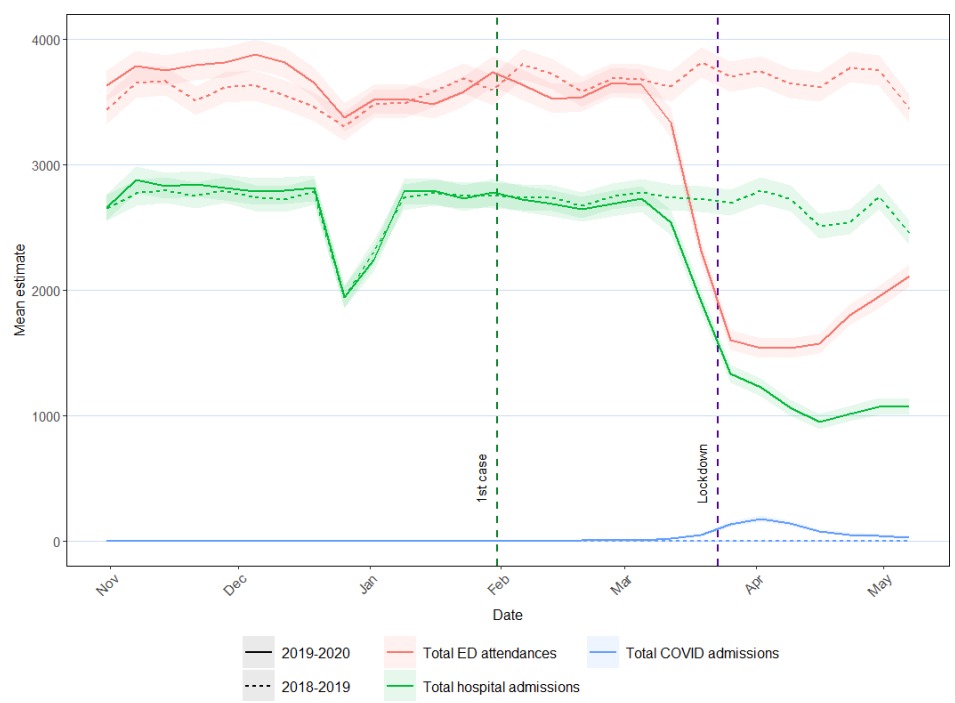

Figure 1 Overall hospital activity (admissions, ED attendances and COVID-19 admissions) between 31 October 2019 and 10 May 2020 compared with the same weeks from 2018 to 2019. Lines describe the mean hospital activities in 2019-2020 (solid) and 2018-2019 (dotted). Shading represents $95 \% \mathrm{Cl}$ of the respective hospital activity. The first case of COVID-19 was on 31 January 2020 and lockdown started on 23 March 2020. ED, emergency department.

deaths due to COVID-19 or to disruptions to healthcare delivery associated with the pandemic (figure 3). His two key messages are: (1) 'the global and national pandemic responses cannot be separated from the cardiovascular health agenda' and (2) 'priorities for cardiovascular science must

pivot, capitalising on lessons learnt during the pandemic'.

Other interesting papers in this issue of Heart include a study by Doris and colleagues ${ }^{4}$ showing that in adults with aortic stenosis CT quantitation of valve calcification is reproducible and

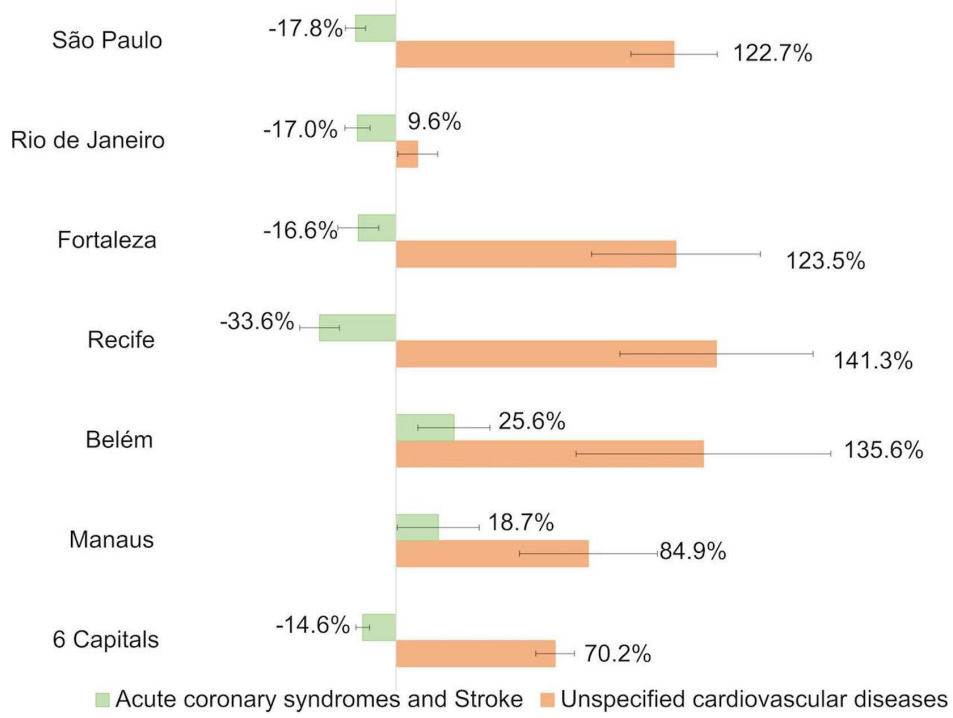

Figure 2 Per cent change with 95\% Cls between the observed and expected number of deaths in 2020 for specified cardiovascular deaths (acute coronary syndromes and stroke) and unspecified cardiovascular diseases per selected six capital cities. 
Policy targets

\begin{tabular}{|c|c|c|c|c|}
\hline \multirow{3}{*}{$\begin{array}{c}\text { Policy } \\
\text { objectives }\end{array}$} & \multirow[b]{2}{*}{$\begin{array}{l}\downarrow \text { COVID-19 } \\
\text { deaths among } \\
\text { persons with } \\
\text { cardiovascular } \\
\text { disease }\end{array}$} & \multicolumn{2}{|r|}{$\begin{array}{l}\text { Healthcare system - } \\
\text { patient interaction }\end{array}$} & Patients \\
\hline & & $\begin{array}{l}\text { Rationalisation of } \\
\text { acute/critical care } \\
\text { resources } \\
\text { Tailored protocols for } \\
\text { cardiovascular } \\
\text { complications }\end{array}$ & $\begin{array}{l}\text { Communication tools } \\
\text { regarding covid-19- } \\
\text { specific risks } \\
\text { Adherence support: } \\
\text { non-pharmaceutical } \\
\text { interventions }\end{array}$ & $\begin{array}{l}\text { Minimisation of } \\
\text { behavioural risks } \\
\text { (prioritise cessation } \\
\text { of smoking) }\end{array}$ \\
\hline & $\begin{array}{l}\downarrow \text { Cardiovascular } \\
\text { deaths among } \\
\text { persons with } \\
\text { cardiovascular } \\
\text { disease }\end{array}$ & $\begin{array}{l}\text { Surety of resources } \\
\text { for acute coronary } \\
\text { syndromes } \\
\text { Rationalisation of } \\
\text { semi-elective } \\
\text { procedures }\end{array}$ & $\begin{array}{l}\text { Promotion of care- } \\
\text { seeking for acute } \\
\text { symptoms } \\
\text { Adherence support: } \\
\text { secondary prevention }\end{array}$ & $\begin{array}{c}\text { Minimisation of all } \\
\text { major behavioural } \\
\text { and environmental } \\
\text { risks }\end{array}$ \\
\hline
\end{tabular}

Figure 3 Critical elements of a comprehensive policy response to cardiovascular disease during COVID-19. The elements proposed above can be modified to fit the resource levels and epidemiological contexts of different countries. Areas marked in red are those likely to translate into the largest short-term mortality gains. Areas marked in yellow or green, while important for prevention, health promotion or stewardship objectives, are less likely to reduce mortality.

demonstrates a greater rate of change in disease severity, compared with echocardiography. Guzzetti and $\mathrm{Clavel}^{5}$ point out that more precise measures of aortic stenosis (AS) severity will allow smaller sample sizes in clinical trials of potential medical therapies, in addition to providing

insights into the pathophysiology of disease progression (figure 4).

In a study of patients undergoing atrial fibrillation (AF) ablation, Piccini and colleagues ${ }^{6}$ found that almost $30 \%$ experienced recurrent atrial tachycardiac (AT) or AF within 3 months. However,

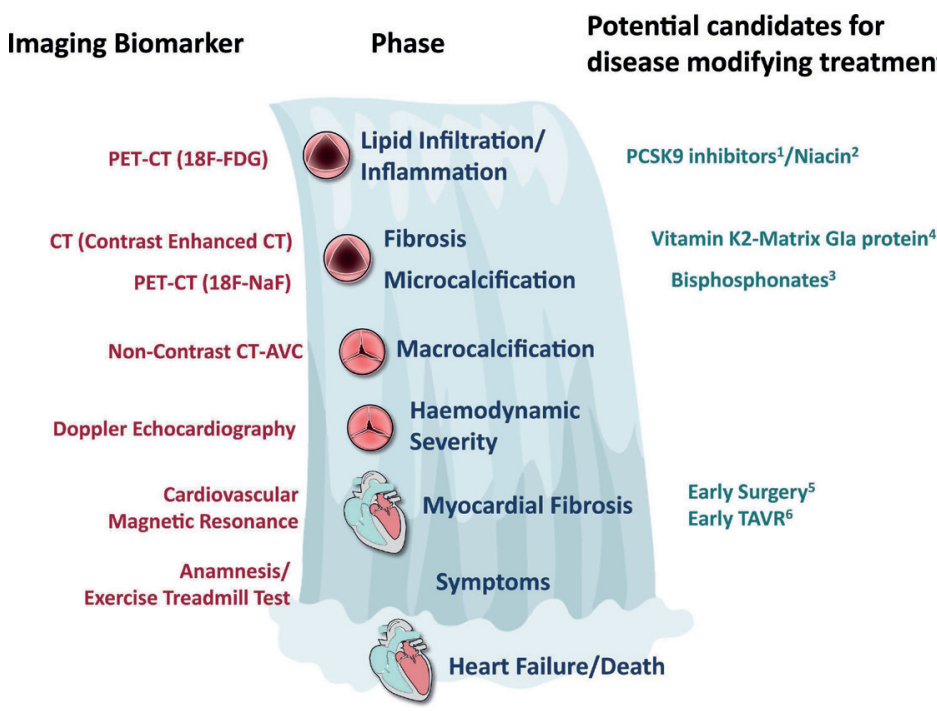

Figure 4 Model of AS progression. Pathophysiological model of serial AS progression ('aortic stenosis cascade', in blue), along with imaging biomarkers targeting each phase (red) and potential disease-modifying treatments being currently tested in randomised clinical trials (green). ${ }^{1}$ South Korean PCSK9 inhibitors (NCT03051360); ${ }^{2}$ EAVaLL: early aortic valve lipoprotein(a) lowering (NCT02109614); ${ }^{3}$ SALTIRE II: study investigating the effect of drugs used to treat osteoporosis on the progression of calcific aortic stenosis (NCT02132026); ${ }^{4}$ BASIK2: bicuspid aortic valve stenosis and the effect of vitamin $\mathrm{K}_{2}$ on calcium metabolism on 18F-NaF PET/MRI (NCT02917525); ${ }^{5}$ EvoLVeD: early valve replacement guided by biomarkers of left ventricular decompensation in asymptomatic patients with severe AS (NCT03094143); ${ }^{6}$ Early TAVR: evaluation of transcatheter aortic valve replacement compared with surveillance for patients with asymptomatic severe aortic stenosis (NCT03042104). 18F-FDG, 18-fluorodeoxyglucose; 18F-NaF, 18-sodium fluoride; AS, aortic stenosis; AVC, aortic valve calcification; PET, positron emission tomography; PCSK9, proprotein convertase subtilisin/kexin type 9; TAVR, transcatheter aortic valve replacement. although those without recurrent AT/AF had greater improvement in functional status, overall quality of life was similar in those with and without AT/AF recurrence. Sridhar and Colbert ${ }^{7}$ discuss the importance of patient-reported outcomes (PROs), not just 'hard' clinical endpoints in clinical trials. 'As researchers and clinicians, our goals must align with those of the patients and what they value. It is heartening to see that more and more clinical trials in cardiology and electrophysiology are incorporating PROs as important endpoints. A slow but definite paradigm shift is occurring to incorporate therapies with a focus on improving patients' lives, not just their hearts.'

The Education in Heart article in this issue discusses the diagnosis and management of familial hypercholesterolemia. ${ }^{8}$ Our Cardiology in Focus article 'What to do when things go wrong' provides a thoughtful discussion of the key steps in dealing with medical error. ${ }^{9}$ The Image Challenge in this issue ${ }^{10}$ provides a concise review of a sophisticated set of possible diagnoses to consider in a patient with a new murmur and classic echocardiographic images. Be sure to look at our online Image Challenge archive with over 150 image-based multiple choice questions and answers (https://heart.bmj.com/pages/collections/ image_challenges/).

Contributors Heartbeat for Heart 106 Issue 24.

Funding The authors have not declared a specific grant for this research from any funding agency in the public, commercial or not-for-profit sectors.

\section{Competing interests None declared.}

Patient and public involvement Patients and/or the public were not involved in the design, or conduct, or reporting, or dissemination plans of this research.

Patient consent for publication Not required.

Provenance and peer review Commissioned; internally peer reviewed.

This article is made freely available for use in accordance with BMJ's website terms and conditions for the duration of the covid-19 pandemic or until otherwise determined by BMJ. You may use, download and print the article for any lawful, non-commercial purpose (including text and data mining) provided that all copyright notices and trade marks are retained.

(c) Author(s) (or their employer(s)) 2020. No commercial re-use. See rights and permissions. Published by BMJ.

D Check for updates

To cite Otto CM. Heart 2020;106:1867-1869.

Heart 2020;106:1867-1869.

doi:10.1136/heartjnl-2020-318627

\section{ORCID iD}

Catherine M Otto http://orcid.org/0000-0002-05279392 


\section{REFERENCES}

1 Ball S, Banerjee A, Berry C, et al. Monitoring indirect impact of COVID-19 pandemic on services for cardiovascular diseases in the UK. Heart 2020;106:1890-7.

2 Brant LCC, Nascimento BR, Teixeira RA, et al. Excess of cardiovascular deaths during the COVID-19 pandemic in Brazilian capital cities. Heart 2020;106:1898-905.

3 Watkins DA. Cardiovascular health and COVID-19: time to reinvent our systems and rethink our research priorities. Heart 2020;106:1870-2.
4 Doris MK, Jenkins W, Robson P, et al. Computed tomography aortic valve calcium scoring for the assessment of aortic stenosis progression. Heart 2020;106:1906-13.

5 Guzzetti E, Clavel M-A. Measuring progression of aortic stenosis: computed tomography versus echocardiography. Heart 2020;106:1873-5.

6 Piccini JP, Todd DM, Massaro T, et al. Changes in quality of life, cognition and functional status following catheter ablation of atrial fibrillation. Heart 2020;106:1919-26.
7 Sridhar AR, Colbert R. Quality of life after atrial fibrillation ablation: measuring the most important end-point. Heart 2020;106:1876-7.

8 Schmidt EB, Hedegaard BS, Retterstøl K. Familial hypercholesterolaemia: history, diagnosis, screening, management and challenges. Heart 2020;106:1940-6.

9 McKenzie $D$. What to do when things go wrong. Heart 2020;106:1947-8.

10 Hayes D, Morgan H, Brown N. New murmur. Heart 2020;106:1926. 